\title{
Lobbying and the Like: Managing the Regulatory Environment
}

\author{
Kelly Martin, Brett Josephson, Gautham Vadakkepatt and Jean Johnson
}

KEYWORDS

\section{Political Management Strategy, Lobbying, Regulations, Pharmaceutical Industry}

THE AUTHORS

\section{Kelly D. Martin}

Professor of Marketing, College of Business, Colorado State University, Fort Collins, CO, USA

kelly.martin@colostate.edu

\section{Brett W. Josephson}

Professor of Marketing, George Mason

University, Fairfax, VA, USA

bjosephs@gmu.edu

\section{Gautham G. Vadakkepatt}

Assistant Professor of Marketing, George Mason University Mason University, Fairfax, VA, USA gvadakke@gmu.edu

\section{Jean L. Johnson}

Emeritus Professor of Marketing, Carson College of Business, Washington

State University, Pullman, WA, USA

johnsonjl@wsu.edu
Facing a flood of regulations $\times$ Companies not only stand up for or against specific matters in plain sight of the customer, they also pursue their interests less publicly in the political arena. Lobbying and other forms of political management are common strategies to influence the regulatory environment in favor of one's company. All around the world, the influence of regulation on the business world has grown, with some countries and industries experiencing dramatic increases. In the past few years, for example, pharmaceutical companies and medical device manufacturers in the EU became subject to a myriad of new or strengthened regulations and forms of oversight on nearly every aspect of their operations. Government oversight via regulations, monitoring, and/or compliance costs has expanded from legal and loss prevention divisions to almost all operations, and they affect many customer-facing product market strategies. In other words, no longer can companies operate in their competitive environment by appealing only to customers. Governments and regulatory bodies increasingly have a say in the ways they create and communicate customer value. Therefore, it is not surprising that companies continue to expand their efforts to proactively manage their regulatory environment. Many companies spend millions of dollars annually on lobbying.

Political marketing strategies and their potential success ׳ Political marketing strategies include activities such as business contributions to political candidates, political action committees (PACs and Super-PACS), and specific bills, plus lobbying, government relations initiatives, and politically-motivated advertising. They represent the predominant means through which companies seek desired policy and legislative ends. Those ends can be regulatory or policy 


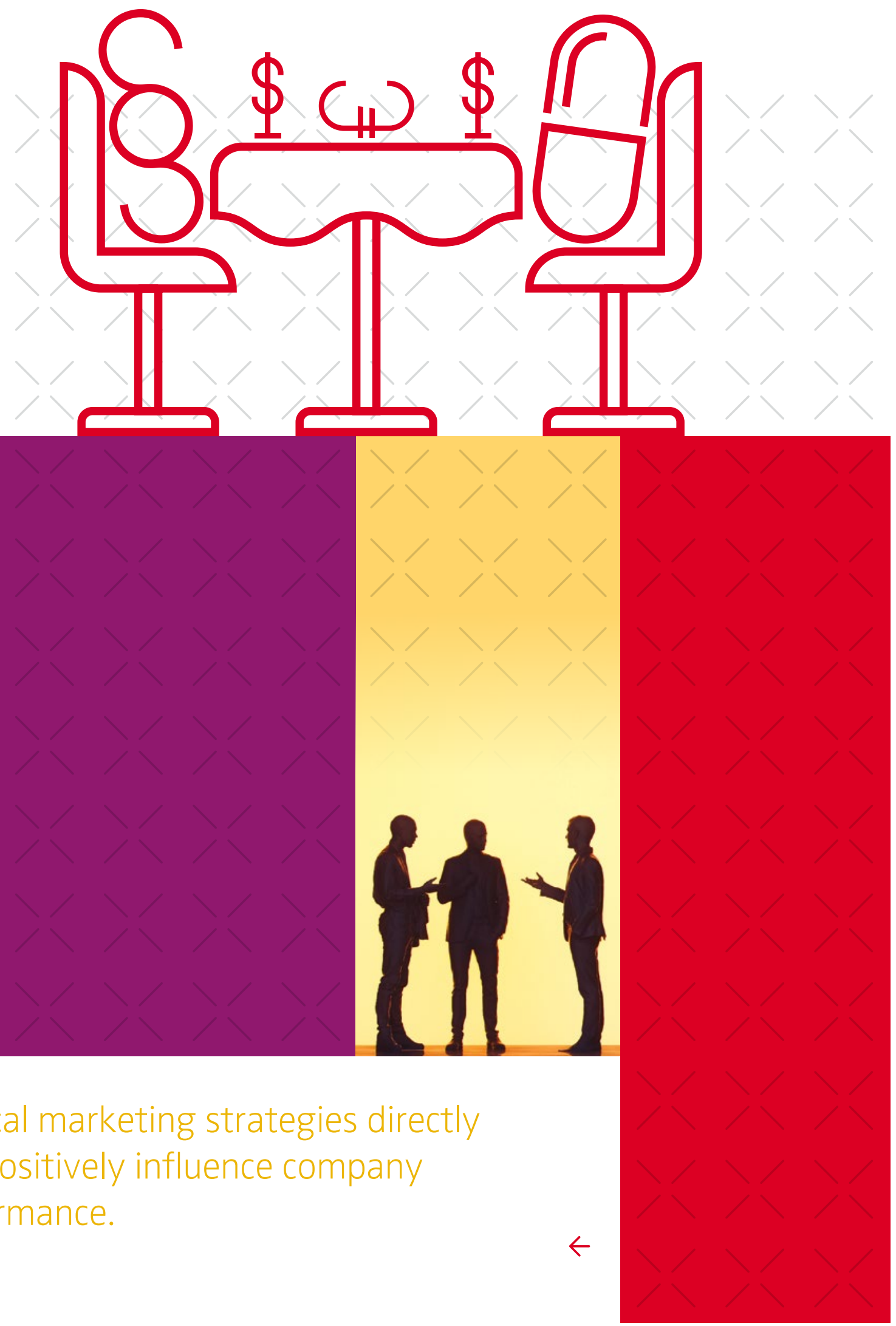

Political marketing strategies directly and positively influence company performance. 


\section{$\gg$ \\ Overall, political marketing strategies increase \\ a company's value. \\ «}

Figure $1>$ Political marketing toolkit and typical objectives
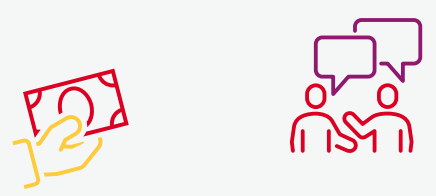

Contributions to political candidates

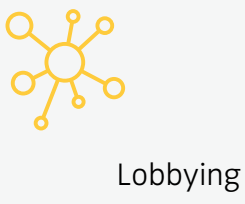

Lobbying

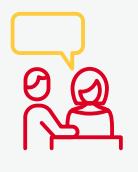

Contributions to PACs and specific bills

Government relations initiatives

Politically-motivated advertising

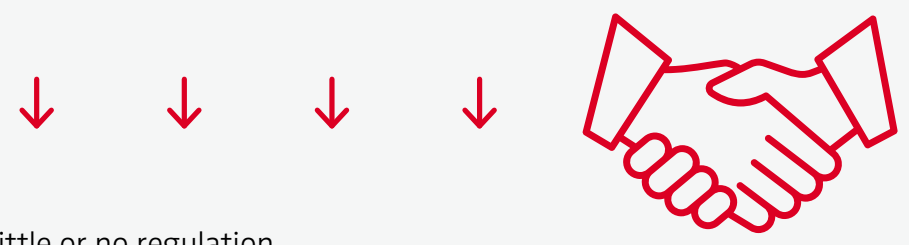

Little or no regulation

Specific regulatory or policy outcomes

Winning government contracts

Favorable tax rates

Relaxed regulatory oversight
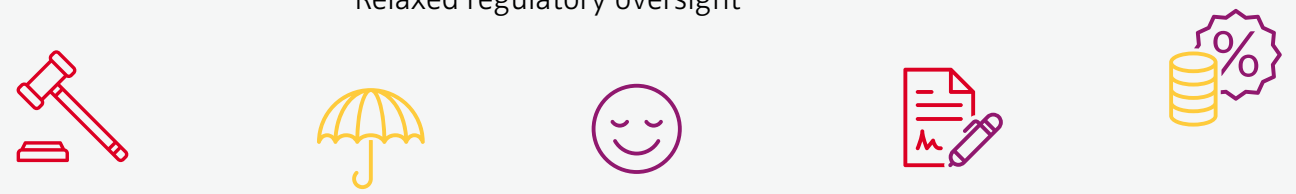

outcomes that affect their company, such as favorable tax rates, winning government contracts, and relaxed regulatory oversight (see Figure 1).

Interestingly, for all the financial and human resources companies devote to political marketing and engaging with regulators and lawmakers, very few see substantive policy changes occur as a result of their efforts. In fact, comprehensive analysis on lobbying shows that, although seeking policy change is one goal, the lobbying efforts by companies preserving a beneficial status quo and forming relationships are the other primary motivations.
Given these long-term and highly uncertain outcomes of political marketing strategies, it is surprising that investors mostly react with enthusiasm to these strategic efforts. Investors who evaluate critical performance metrics, such as market valuation and risk, clearly pay attention to how companies engage with governments and regulators and adjust their assessments accordingly - usually in a positive way. Moreover, conventional wisdom that has accumulated from academic research on the topic also seems to suggest that all political maneuvering is good for a company's financial performance. In the study below, we investigated whether such enthusiasm is justifified (Box 1). 
BOX 1

\section{The study and main findings}

For our study, we focused on the pharmaceutical sector and tracked pharmaceutical and medical device companies traded on U.S. stock exchanges in the period 20032014. This sector is the most generous political spender among all industries and an exemplar of particularly strong regulatory and political elements. The pharmaceutical industry is further charcterized by high R\&D investments and advertising spendings. We extracted each company's political marketing expenditures from government-mandated reporting databases, and also pulled their performance metrics and R\&D and advertising spending. With our study, we attempted to learn more about investor reactions and the interdependence between R\&D, advertising, and political marketing.

The results of our analyses show that political marketing strategies directly and positively influence performance, but they also interact with the companies' strategies aimed at the competitive environment such as R\&D and advertising.
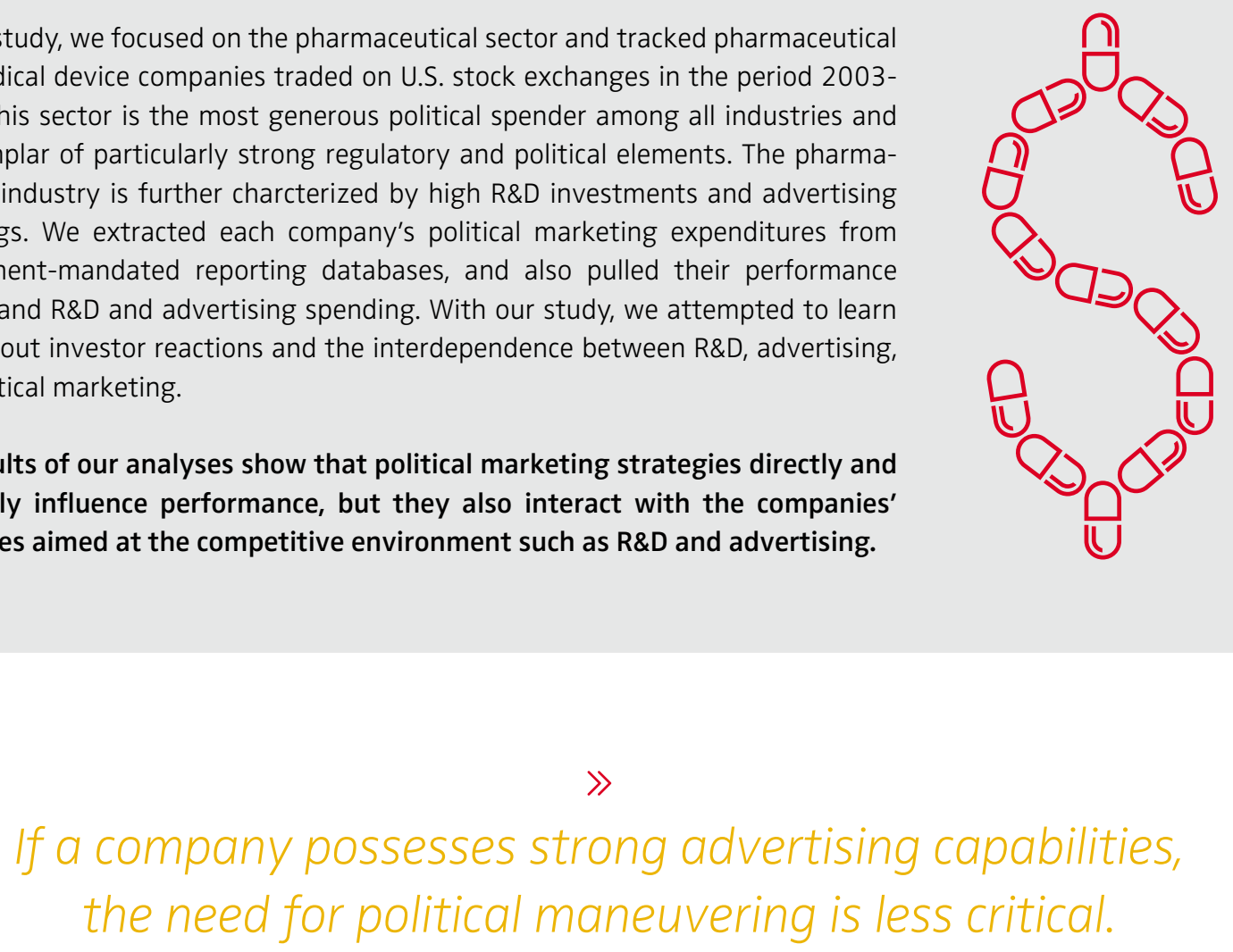

$\ll$

\section{A closer look at the effects of political marketing and its interrelations with corporate value creation and commu- nication efforts $\times$}

$>$ Political marketing strategies increase company value and decrease market-based risk $x$ Overall, political marketing strategies increase a company's value. Investors seem to view political marketing strategies as an expected part of doing business in pharmaceuticals and they seem to expect that such strategies provide a shield against market fluctuations. Indeed, our results confirmed that political marketing reduces market based risks. Lobbying or government relations can act as a form of insurance during economic downturn and the companies might be more likely to receive government assistance during economic hardships.
> Expertise in R\&D reduces the need for political marketing $\times$ Yet, in some combinations, political marketing strategies interact with a company's R\&D investments to lower its value while increasing company specific risk. This finding suggests that financial markets view political marketing strategies and R\&D as substitutes. In other words, if a company is highly capable in R\&D, especially in an industry that is as innovation-intensive as pharmaceuticals, the merits of those innovations can create company value on their own and less political maneuvering should be required. On the other hand, companies that are weak or unskilled in R\&D and provide products of lower quality and safety or with other performance deficiencies may benefit from lobbying. They are more dependent on regulatory and policy benefits of their political marketing than peers with stronger R\&D. 
Box 2

\section{Lobbying and the consumer}

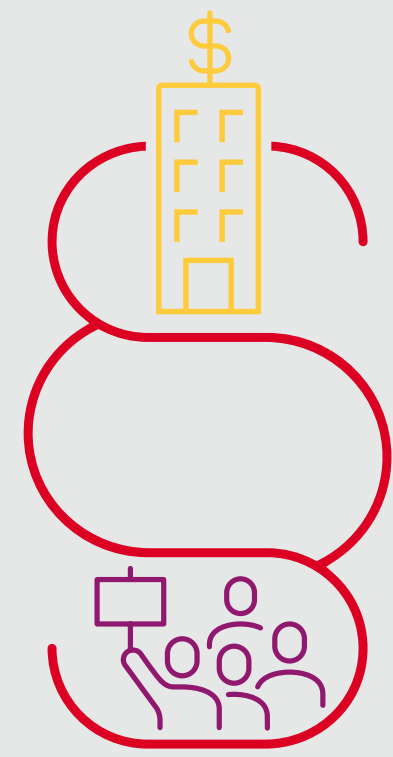

Public opinion polling shows that consumers express strong disdain for corporate lobbying practices. In general, people feel negatively about connections they perceive as too close between business and government: When companies have disproportionate influence over the regulatory environment that is supposed to monitor and keep their actions in check, these companies might be more likely to do whatever they want - at the expense of consumer interests. Instead of trying to appease their customers by creating and delivering superior value, managers might rely on benefits from governments. Political marketing could even motivate governments to help create and protect markets that benefit the company. All of these potential lobbying outcomes create opportunities for abuse of corporate political influence and leave consumers feeling powerless.

However, in many cases, companies spend time lobbying government agencies for regulatory preferences that can work to benefit customers. These benefits may include removing regulatory hurdles that prevent customers from accessing new products or innovative solutions. In the case of pharmaceuticals or medical devices, when companies lobby for expedited product approval, for example, customers often gain access to lifesaving treatments or boosts to their quality of life more quickly than if the firm had not lobbied.

$>$ High innovation potential plus intensive political marketing work well together $\ltimes$ On the other hand, we identified that very high levels of both R\&D and political marketing can work as complements and can lead to positive outcomes. In this case, we infer that investors see very high R\&D, or strong innovation potential, as being enhanced by political efforts. Think about the political and regulatory connections that smooth drug approval processes, open entry into new markets, enable off-label product uses, or protect valuable patents. In this case, political efforts can directly support customer value creating investments such as R\&D. Financial markets see this combined effort and infer positive signals around company performance.

> Strong advertising makes political maneuvering less critical $\ltimes$ When looking at how political marketing strategies interact with companies' advertising investments, we find that they only interact to affect market-based risk, again showing substitution. If a company possesses strong advertising capabilities, the need for political maneuvering is less critical. As with the combined effects with R\&D, political maneuvering combined with advertising worked to shield the firm from overall market risk, but with regard to firm value it was viewed as unnecessary.

\section{Political management capital can be small money with} large impact $\times$ In our analyses, we also tested the elasticities of investments in political marketing, R\&D, and advertising, and found that the return on investment in political management capital was much larger than for advertising or R\&D capital. The added ability of lobbying and the like to reduce market-based risk interactively with both $R \& D$ and advertising provides an important form of business insurance and might explain why investors reward companies' political maneuvers. As most industries face increased regulatory oversight in some form, marketing managers should consider political marketing strategies as a viable part of their toolkit, perhaps even championing their use. 


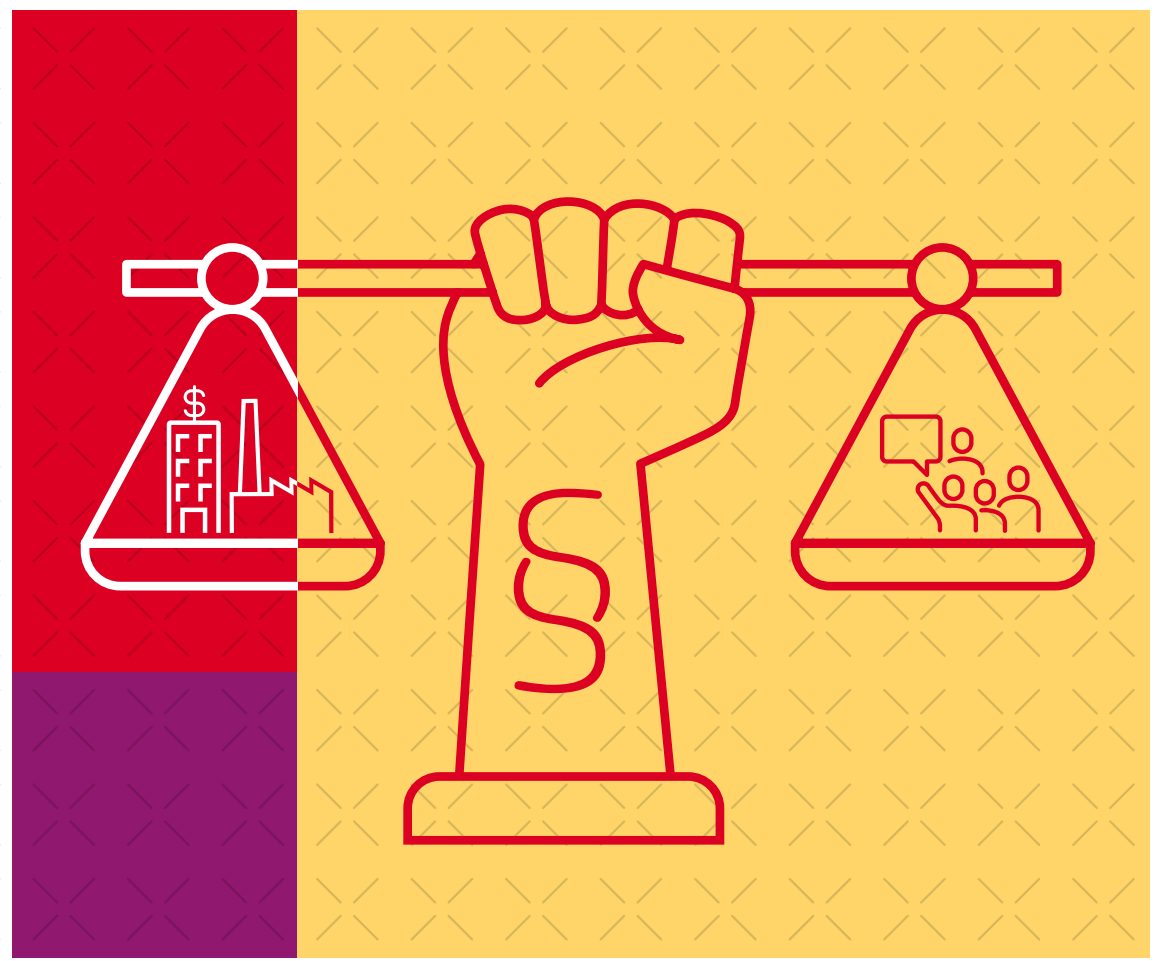

In many combinations, political marketing strategies are beneficial for companies and worth the effort. Companies that lobby enjoy greater market value, stronger ROA, can gain disproportionate benefits, and wield power. When investors learn of lobbying, they reward these companies accordingly. Among consumers and the general public, on the other hand, lobbying has a bad reputation, regardless of the potential benefits - despite potential direct positive effects for customers (see Box 2). Thus, while lobbying and lobbyists are considered some of the least ethical corporate activities by the general public, investors still view them as potent sources of positive performance. With a longer-term perspective, lobbying companies and governments alike might be well advised to take the reputation problem of political marketing seriously and install rules to avoid the abuse of power of all parties involved. 